\section{Visual and anatomical outcomes following vitrectomy for complications of diabetic retinopathy: The DRIVE UK Study}

${ }^{1}$ Laser and Retinal Research Unit, Department of Opthalmology, King's College Hospital, London, UK

${ }^{2}$ St. Thomas' Hospital, London, UK

Correspondence: B Gupta, Retina Research Fellow, Laser and Retinal Research Unit, Department of Ophthalmology, King's College Hospital,

King's College Hospital NHS Trust, Denmark Hill, London SE5 9RS, UK

Tel: + 44 (0)20 32994748 ;

Fax: + 44 (0)20 32993738

E-mail: Bhaskar.Gupta@

nhs.net

Received: 3 May 2011 Accepted in revised form: 9 November 2011 Published online: 6 January 2012

Meeting Presentation: Poster Presentation: SN- ARVO: Diabetic update, Chennai, India, September 2010.

\begin{abstract}
Introduction End-stage diabetic eye disease is an important cause of severe visual impairment in the working-age group. With the increasing availability of refined surgical techniques as well as the early diagnosis of disease because of screening, one would predict that the prevalence of this condition is decreasing and the visual outcome is improving.

Aim To study the prevalence and visual outcome following vitrectomy for complications of diabetic retinopathy. Materials and methods This study identified the patients who underwent vitrectomy from January 2007 to December 2009 because of diabetes-related complications in South East London. Data collected included baseline demographics, best-corrected visual acuity, indication for the vitrectomy, complication, outcome, and duration of follow-up. Results The prevalence of people requiring vitrectomy who are registered in the diabetes register of this region was 2 per 1000 people with diabetes. Vitrectomy was required in 185 eyes of 158 patients during this period. These included 83 Caucasians, 51 Afro-Caribbeans, 17 South Asians, and 7 from other ethnic groups. There were 58 patients with type I diabetes and 100 with type II, with a mean duration of diabetes of 23 and 16.5 years, respectively. The reason for vitrectomy included tractional retinal detachment (TRD) in 109 eyes, non-clearing vitreous haemorrhage (NCVH) in 68 eyes, and other causes in 8 eyes. In all, $50 \%$ of the eyes with TRD and NCVH, and $87 \%$ of the eyes
\end{abstract}

B Gupta', S Sivaprasad', R Wong², A Laidlaw², TL Jackson', D McHugh" and TH Williamson ${ }^{2}$ with NCVH improved by at least three ETDRS lines at 12 months. Poor predictors of visual success included longer duration of diabetes (OR: 0.69), use of insulin (OR: 0.04), presence of ischaemic heart disease (OR: 0.04), delay in surgery (OR: 0.59), and the failure to attend clinic appointments (OR: 0.58). Preoperative use of intravitreal bevacizumab in eyes with TRD undergoing vitrectomy showed a marginal beneficial effect on co-existent maculopathy $(P=0.08)$ and required less laser intervention post procedure, but did not affect the number of episodes of late-onset vitreous haemorrhage post vitrectomy $(P=0.81)$. Conclusion Visual outcome has improved significantly in eyes with complications due to diabetic retinopathy compared with the previously reported Diabetic Vitrectomy Study.

Eye (2012) 26, 510-516; doi:10.1038/eye.2011.321; published online 6 January 2012

Keywords: pars plana vitrectomy; proliferative diabetic retinopathy; tractional retinal detachment; non-clearing vitreous haemorrhage

Introduction

End-stage diabetic eye disease is an important cause of severe visual impairment in the working-age group. ${ }^{1,2}$ Tractional retinal detachment (TRD) and non-clearing vitreous haemorrhage $(\mathrm{NCVH})$ are two common complications. ${ }^{3}$ Since the Diabetic Retinopathy Vitrectomy Study over 25 years ago, there has been significant advancement in surgical 
techniques such as the use of a wide-angled viewing system, use of a perioperative endolaser, ${ }^{4,5}$ small-gauge vitrectomy, and use of anti-vascular endothelial growth factor adjuvants before surgery. ${ }^{6}$ Also, with the early diagnosis of disease from screening, one would predict that the prevalence of this end-stage condition is decreasing and the visual outcomes are improving.

The purpose of this study is to report the recent visual and anatomical outcomes of patients undergoing pars plana vitrectomy (PPV) for complications due to proliferative diabetic retinopathy.

\section{Materials and methods}

The data were collected as part of the Diabetic Retinopathy In Various Ethnic groups (DRIVE-UK) Study. DRIVE-UK is a cross-sectional population-based study that identified patients with diabetes from the Diabetic Eye Complication Screening services in South East London. As a subset, this study also identified patients who underwent vitrectomy between January 2007 and December 2009 because of diabetes-related complications in South East London. All the patients underwent standard three-port $20 \mathrm{G}$ PPV without the use of a chandelier. A retrospective case-note review was performed at King's College Hospital and St Thomas' Hospital, London, UK. The patients were divided into three main groups according to the primary indication for vitrectomy:

Group A: TRD with/without haemorrhage

Group B: NCVH (of at least 3 months duration) secondary to proliferative diabetic retinopathy (PDR)

Group C: Others (tractional diabetic macular oedema, epiretinal membrane, etc)

Data collected included baseline demographics, best-corrected visual acuity (VA), indication for the procedure, peri- and postoperative complication, anatomical and visual outcome, and duration of follow-up. Additional information included date of diagnosis of PDR, time delay in surgery, use of intravitreal bevacizumab as an adjuvant, and appointments attended and failed by patient.

\section{Outcome measures}

The primary outcome measure was the proportion of patients with visual success. Visual success was defined as $\geq 15$ letters gained from baseline VA at 12 months follow-up.

Secondary outcomes were: (1) mean change in VA at 12 months; (2) anatomical outcome (anatomic success was defined as attaining a flat retina without tamponade at 12 months); (3) effects of bevacizumab on post vitrectomy vitreous haemorrhage $(\mathrm{PVVH})$ and the need for macular laser for new-onset macular oedema postoperatively; (4) systemic factors that predicted visual success; (5) effect of ethnicity: the three main ethnic groups evaluated were Caucasians, Afro-Caribbeans (ACs), and South Asians; (6) effect of missed appointments in clinic (the number of failed and attended appointments in the eye clinic from the date of decision to operate to the last follow-up was recorded from the hospital electronic record system); (7) rate of postoperative complications such as retinal detachment, cataract, and glaucoma.

PVVH was classified into three groups:

$\begin{array}{lll}\text { Group I } & \text { Persistent } & \text { Day } 1 \text { postoperative day } \\ \text { Group II } & \text { Early } & \geq 1 \text { month } \\ \text { Group III } & \text { Late } & >1 \text { month }\end{array}$

\section{Statistical test}

SPSS 17.0. software (SPSS, Chicago, IL, USA) was used for statistical analysis. Each patient underwent bestcorrected VA test using Snellen VA and it was converted to ETDRS letters for study analysis: CF and HM were assigned values of 5 and 0 letters, respectively, according to the approximate ETDRS letter chart. ${ }^{7}$ Multiple linear regression and ANOVA tests were performed, to explore the significant predictors of visual gain of $\geq 15$ ETDRS letters at 12 months. If the patient had operations in both eyes, only the first operated eye was included in the analysis to eliminate confounding factors. Statistical significance was set at $P<0.05$ for all analyses. Group $C$ was ignored from regression analysis because of fewer numbers.

\section{Ethics approval}

The local Ethics Committee and the Clinical Effectiveness Department of the King's College Hospital approved this study (CASS AP0861-01).

\section{Results}

\section{Patient demographics}

A total of 31773 people with diabetes were registered in the diabetic retinopathy register in South East London and the rate of vitrectomy was 2 per 1000 per year in patients with end-stage diabetic eye disease. There were more Caucasians, males, and patients with type II diabetes (Table 1). The mean age of the study population was 54.08 years (SD \pm 14.15 ), and duration of diabetes was 23.12 years $(\mathrm{SD} \pm 8.82)$ in type I and 17.1 years (SD \pm 8.12 ) years in type II, respectively. 
In this study, a total of 110 patients were on treatment for lower blood pressure, 96 were on cholesterollowering agents, 13 patients with type I and 29 with type II diabetes had ischaemic heart disease (IHD), 13 with type I and 10 with type II were on renal dialysis, and 4 each with type I and type II had co-existent cerebrovascular accidents.

Table 1 Baseline demographics

\begin{tabular}{lrrr}
\hline & Frequency & $\%$ & P-value \\
\hline Ethnicity $(n=158)$ & & & \\
$\quad$ Caucasian & 83 & 52.53 & $\chi^{2}: 97.03, P=0.00$ \\
$\quad$ Afro-Caribbean & 51 & 32.28 & \\
$\quad$ South Asian & 17 & 10.75 & \\
Others & 7 & 0.04 & \\
& & & \\
Gender ( $n=158)$ & & & \\
$\quad$ Male & 85 & 54.1 & $\chi^{2}: 1.62, P=0.20$ \\
Female & 73 & 45.9 & \\
& & & \\
Type of diabetes $(n=158)$ & & & \\
$\quad$ Type I & 58 & 36.8 & $\chi^{2}: 13.39, P=0.000$ \\
$\quad$ Type II & 100 & 63.2 & \\
& & & \\
Indication for surgery $(n=185)$ & & \\
$\quad$ Group A & 117 & 63.24 & $\chi^{2}: 76.95, P=0.00$ \\
$\quad$ Group B & 60 & 32.43 & \\
$\quad$ Group C & 8 & 4.32 & \\
\hline
\end{tabular}

\section{Visual and anatomical outcomes}

Overall, 93.2\% eyes in group A and 100\% in group B and $C$ had stable vision (loss of $<15$ letters). In all, $29.05 \%$ in group A, 65\% in group B, and $100 \%$ in group C had a final VA of $\geq 6 / 12$ (LogMAR $\geq 0.3$ ). Table 2 shows the visual outcomes for each indication of vitrectomy.

There was a mean gain of $18.08 \pm 27.08$ ETDRS letters in group A, 42.02 \pm 27.17 ETDRS letters in group B, and $17.37 \pm 26.13$ ETDRS letters in group C. Overall, $6.4 \%$ of the patients had a best-corrected Snellen VA of $\leq 6 / 60$ in the better eye and were certified as visually impaired, as defined by the National Screening Committee, UK (http://www.retinalscreening.nhs.uk).

As ethnicity was found to be an independent risk factor for visual impairment and severity of diabetic retinopathy in the total cohort of people with diabetes in this region as part of this ongoing DRIVE-UK Study (unpublished data), we estimated the visual outcome of vitrectomy in each ethnic group (Table 3). Ethnic minorities had an average of 5.55 fewer letters than Caucasians, but minority status did not affect the final visual outcome after controlling for all other factors.

The overall anatomic success in this series was $84.32 \%$.

\section{Effect of bevacizumab}

In group A, 30 patients non-randomly received bevacizumab before vitrectomy. The dose used was

Table 2 Visual outcome in patients following vitrectomy at 12 months

\begin{tabular}{|c|c|c|c|c|c|c|}
\hline & \multicolumn{2}{|c|}{$\geq 15$ letters gain } & \multicolumn{2}{|c|}{ \pm 15 letters } & \multicolumn{2}{|c|}{$\geq 15$ letters loss } \\
\hline & $\begin{array}{c}\text { First operated } \\
\text { eye }^{\mathrm{a}}, \mathrm{N}(\%)\end{array}$ & $\begin{array}{l}\text { All eyes, } \\
\mathrm{N}(\%)\end{array}$ & $\begin{array}{c}\text { First operated } \\
\text { eye }^{\mathrm{a}}, \mathrm{N}(\%)\end{array}$ & $\begin{array}{l}\text { All eyes, } \\
\mathrm{N}(\%)\end{array}$ & $\begin{array}{c}\text { First operated } \\
\text { eye }^{\mathrm{a}}, \mathrm{N}(\%)\end{array}$ & $\begin{array}{l}\text { All eyes, } \\
\mathrm{N}(\%)\end{array}$ \\
\hline Group A & $45(46.4)$ & $58(49.6)$ & $46(47.4)$ & $51(43.6)$ & $6(6.2)$ & $8(6.8)$ \\
\hline Group B & $46(88.6)$ & $51(85.0)$ & $6(11.4)$ & $9(15.0)$ & $0(0.0)$ & $0(0.0)$ \\
\hline Group C & $3(42.8)$ & $3(37.5)$ & $4(57.2)$ & $5(62.5)$ & $0(0.0)$ & $0(0.0)$ \\
\hline
\end{tabular}

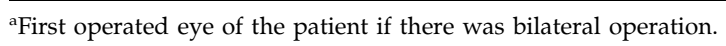

Table 3 Visual outcome in patients following vitrectomy by ethnicity and indication

\begin{tabular}{|c|c|c|c|c|c|c|c|c|c|}
\hline & \multicolumn{3}{|c|}{ Tractional retinal detachment (TRD) } & \multicolumn{3}{|c|}{ Non-clearing vitreous haemorrhage (NCVH) } & \multicolumn{3}{|c|}{ Other } \\
\hline & $\begin{array}{l}\text { Baseline } \\
\text { VA }\end{array}$ & $\begin{array}{c}\text { Final } \\
\text { VA }\end{array}$ & $\begin{array}{c}\text { Mean } \\
\text { change } \\
V A\end{array}$ & $\begin{array}{l}\text { Baseline } \\
\text { VA }\end{array}$ & $\begin{array}{c}\text { Final } \\
\text { VA }\end{array}$ & $\begin{array}{c}\text { Mean } \\
\text { change } \\
V A\end{array}$ & $\begin{array}{l}\text { Baseline } \\
\text { VA }\end{array}$ & $\begin{array}{c}\text { Final } \\
V A\end{array}$ & $\begin{array}{c}\text { Mean } \\
\text { change } \\
V A\end{array}$ \\
\hline $\begin{array}{l}\text { Afro-Caribbean } \\
(n=51)\end{array}$ & $26.91 \pm 18.34$ & $35.76 \pm 27.20$ & $8.83 \pm 26.91$ & $14.42 \pm 16.71$ & $60.52 \pm 26.94$ & $46.11 \pm 26.13$ & $58.0 \pm 2.8$ & $65.0 \pm 14.14$ & $7.0 \pm 11.3$ \\
\hline $\begin{array}{l}\text { Caucasian } \\
(n=83)\end{array}$ & $19.71 \pm 18.75$ & $41.73 \pm 27.53$ & $22.03 \pm 27.39$ & $23.15 \pm 18.52$ & $66.55 \pm 27.37$ & $43.39 \pm 27.41$ & $44.2 \pm 20.67$ & $62.8 \pm 29.82$ & $18.6 \pm 28.95$ \\
\hline $\begin{array}{l}\text { South Asian } \\
(n=17)\end{array}$ & $22.30 \pm 16.09$ & $53.30 \pm 25.10$ & $31.10 \pm 26.05$ & $17.86 \pm 17.81$ & $52.43 \pm 27.32$ & $34.57 \pm 27.82$ & 48.0 & 80.0 & 32.0 \\
\hline$P$-value & 0.44 & 0.06 & 0.04 & 0.10 & 0.25 & 0.17 & 0.60 & 0.68 & 0.29 \\
\hline
\end{tabular}

Abbreviation: VA, visual acuity. 
$1.25 \mathrm{mg} / 0.05 \mathrm{ml}$, at a median of 7 days (range 4-7) before vitrectomy. The odds of late PVVH was equal for bevacizumab (16/30) and non-bevacizumab patients (35/67), being 55\% $(P=0.81)$.

Only $2 / 30(6 \%)$ of the eyes that received bevacizumab developed clinically significant macular oedema that required laser treatment in comparison with 14/67 (20.9\%) eyes that did not receive bevacizumab. This difference was not statistically significant $(P=0.08)$.

\section{Effect of systemic factors}

A logistic regression was performed (Table 4) to explore the baseline systemic factors that were significant predictors of visual success of the operation. Group C was ignored in the regression model because of very few numbers. The overall regression was significant, $\chi^{2}(28)=82.57, P<0.001$, for a Cox and Snell $R^{2}=0.506$ and Nagelkerke $R^{2}=0.700$, meaning that the collective set of predictors were able to predict between an estimated 51 and $70 \%$ of the variance in the likelihood of an operation to be a complete success.

Duration of diabetes $(P=0.01)$ was a significant predictor for likelihood of visual success. For each year the patient had had diabetes, the odds decreased by 0.69 for successful outcome. Likewise, if the patient was on insulin, the odds of visual success decreased by 0.04 $(P=0.02)$. Presence of IHD was also a significant negative predictor (OR: $0.047, P=0.01$ ).

Time interval in months from decision to operate by the physician, as demonstrated by progressive TRD involving macular or $\mathrm{NCVH}$, to the date of operation was also a significant negative predictor, with each month delay resulting in a decrease in the likelihood of success, with an OR of $0.59, P=0.021$.

\section{Effect of missed preoperative hospital appointments}

For each missed appointment/cancellation by patients in group A, there was an estimated letter loss of 2.09 letters $(P=0.033)$. Similarly, for each missed appointment/ cancellation by patients in group $B$, there was an estimated letter loss of 2.40 letters $(P=0.033)$.

\section{Complications}

Re-detachment and final retina status

A total of 36/117 (30.7\%) eyes in group A underwent redo-vitrectomy. In group A, 17/36 (47.2\%) of the reoperations were for re-detachment of the retina, 14/36 (38.9\%) for $\mathrm{NCVH}$, and 5/36 (13.9\%) for epi-retinal membrane. Further subanalysis revealed that only $18.60 \%$ with TRD only at primary presentation had a reoperation, whereas the rate increased to $36.8 \%$ when combined TRD and VH was present at primary vitrectomy $(P<0.05)$. In group B with $\mathrm{NCVH}, 5 / 60$ $(8.3 \%)$ underwent redo vitrectomy, $3 / 5$ for NCVH and $2 / 5$ for retinal detachment. Moreover, $11.35 \%$ (21/185) of the eyes either had detached retina or developed into phthisis at 12 months. The rates of reoperations were $14.2 \%$ in South Asians, $20.7 \%$ in Caucasians, and $24.24 \%$ in ACs, respectively.

\section{Cataract}

In all, $51(27.57 \%)$ eyes had prior cataract extraction and $41(22.62 \%)$ eyes required cataract operation at a mean of 8.01 months following primary vitrectomy. Also,

Table 4 Logistic regression analysis showing the effect of various systemic variables

\begin{tabular}{|c|c|c|c|c|c|c|}
\hline \multirow[t]{2}{*}{ Variable } & \multirow[t]{2}{*}{ B } & \multirow[t]{2}{*}{$S E$} & \multirow[t]{2}{*}{ P-value } & \multirow{2}{*}{$\begin{array}{l}\text { Odds ratio } \\
\quad(O R)\end{array}$} & \multicolumn{2}{|c|}{ 95\% C.I. for $O R$} \\
\hline & & & & & Lower & Upper \\
\hline Age & -0.05 & 0.06 & 0.39 & 0.95 & 0.85 & 1.07 \\
\hline Male & 0.78 & 0.86 & 0.36 & 2.18 & 0.41 & 11.69 \\
\hline Type I diabetes & 1.65 & 2.09 & 0.43 & 5.22 & 0.09 & 316.65 \\
\hline Duration of diabetes & -0.37 & 0.15 & 0.01 & 0.69 & 0.52 & 0.92 \\
\hline $\mathrm{HbA1c}$ & 0.01 & 0.24 & 0.98 & 1.01 & 0.63 & 1.60 \\
\hline Hypertension & -2.410 & 1.32 & 0.07 & 0.09 & 0.01 & 1.20 \\
\hline Systolic BP & 0.06 & 0.03 & 0.03 & 1.06 & 1.01 & 1.12 \\
\hline Diastolic BP & -0.10 & 0.06 & 0.07 & 0.90 & 0.81 & 1.01 \\
\hline Co-existent ischaemic heart disease (IHD) & -3.06 & 1.19 & 0.01 & 0.05 & 0.010 & 0.48 \\
\hline Serum total cholesterol & 2.00 & 1.18 & 0.07 & 7.39 & 0.84 & 64.79 \\
\hline Co-existent cerebrovascular accident (CVA) & -0.31 & 1.61 & 0.85 & 0.74 & 0.03 & 17.36 \\
\hline Interval (months) for the clinician to make the decision to operate & -0.51 & 0.22 & 0.02 & 0.60 & 0.39 & 0.92 \\
\hline Intravitreal bevacizumab & -0.88 & 0.90 & 0.33 & 0.41 & 0.07 & 2.43 \\
\hline Appointments not attended by the patient & -0.54 & 0.19 & 0.01 & 0.58 & 0.40 & 0.86 \\
\hline
\end{tabular}

Abbreviation: B, unstandardized coefficient. 
$26(14.05 \%)$ eyes had combined primary vitrectomy and cataract extraction. Two eyes had subsequent zonular dialysis, one eye had dropped nucleus during cataract extraction following vitrectomy, and one eye had subluxated IOL.

\section{Glaucoma}

Overall $8.2 \%(13 / 158)$ of patients were on new IOP-lowering drugs. Two of these required the cyclodiode procedure and $81.2 \%$ of the new ${ }^{8}$ patients were controlled on one drop. There was no difference in IOP with the type of tamponade used during the primary vitrectomy.

\section{PVVH}

In all, $43.25 \%$ of the eyes had post-vitrectomy haemorrhage, with the majority (31.89\%) occurring on the first postoperative day (Table 5). Overall $9.7 \%$ of the eyes required redo vitrectomy for recurrent vitreous haemorrhage.

\section{Discussion}

Surgical management of late complication of proliferative diabetic retinopathy to date remains one of the most complex and challenging vitreo-retinal procedures. However, both anatomical and visual results (Table 6) have continued to improve since the reported Diabetic Vitrectomy Study. ${ }^{4,9,10}$ It is difficult to compare results from different studies owing to the presence of numerous confounding factors and significant systemic comorbidities in people with a long duration of diabetes. In addition, a lack of universal grading of vitreo-retinal adhesion and TRD adds to the confusion.

Table 5 Frequency of post vitrectomy haemorrhage

\begin{tabular}{lcrl}
\hline & N (Total=185) & \multicolumn{1}{c}{$\%$} & Mean episodes \\
\hline Group I & 59 & 31.89 & 1.23 (range 1-3) \\
Group II & 15 & 8.10 & 1.47 (range1-2) \\
Group III & 6 & 3.20 & 1.1 (range1-2) \\
No Haemorrhage & 105 & 56.75 & \\
\hline
\end{tabular}

Although the outcomes of published series on this subject are measured at different time-points postoperatively (Table 6), it is useful to note that the visual outcomes are continuing to improve. In our study $60.5 \%$ of all eyes showed $\geq 3$ ETDRS line improvement and $38.38 \%$ of all cases had a final VA of $\geq 6 / 12(20 / 40)$, which represents a marked improvement from the recently published series (Table 6) by Yorston et $a l^{11}$ and earlier reported studies by Thompson et $a l^{12}$ and the Diabetic Retinopathy Vitrectomy Study. ${ }^{13}$ In the study by Yorston et al, $14.2 \%$ patients were of AC origin compared with $32.4 \%$ in our cohort. AC patients have more chronic and complex disease with broader vitreo-retinal adhesions ${ }^{8}$ and this may explain the higher complication rates observed in our study. Also, the surgical approach was to remove epiretinal membranes uncompromisingly, which may partly explain the higher complication rates. In the study by Yorston et $a{ }^{11}{ }^{11} 43.2 \%$ of the patients had primary vitrectomy for NCVH compared with $32.4 \%$ in our cohort, which has a greater likelihood of visual success. Moreover, higher rates for redo procedures observed in eyes with combined TRD and NCVH compared with TRD or NCVH alone may indicate underlying active membranes, vitreous shrinking, or PVR production. Surgery in these unstable eyes probably predisposes to high postoperative complications. In our study, $50.81 \%$ eyes required some tamponade at the end of primary vitrectomy and silicon oil was only used in 9/185 of the eyes. This again may be responsible for the better visual outcome seen in this series, and for the lower complications commonly seen with use of silicon oil like redo surgery, toxicity, and raised pressure. New techniques involving bimanual surgery should be investigated for improved rates of iatrogenic tear creation and improved surgical outcomes.

The overall improved results seen in our study could be multi-factorial: improved health-care services and better awareness of both primary health-care service providers and patients to improved diabetic control and other systemic co-morbidities. The establishment of the national diabetic retinopathy screening programmes may also contribute to the low prevalence of vitrectomies in diabetic eye disease today. Poor postoperative outcome in patients with IHD and use of insulin may again reflect

Table 6 Comparative visual outcome following vitrectomy for proliferative diabetic retinopathy

\begin{tabular}{|c|c|c|c|c|}
\hline & $D R V S(\mathrm{n}=987)$ & Steel et al $(\mathrm{n}=129)$ & Yorston et al $(\mathrm{n}=174)$ & DRIVE UK $(\mathrm{n}=185)$ \\
\hline TRD & $60 \%$ & $\begin{array}{l}48 \% \text { but severe cases excluded } \\
\text { (patients with oil excluded) }\end{array}$ & $32 \%$ & $63 \%$ \\
\hline Vision & $15-20 \%$ at least $6 / 12$ & NA & $11 \%$ better than $6 / 12$ & $38 \%$ at least $6 / 12$ \\
\hline Postoperative RD & $12-21 \%$ & $1.1 \%$ & $3 \%$ (but $6 \%$ no view at follow-up) & $10 \%$ \\
\hline NPL & $19-25 \%$ & $0 \%$ & $2 \%$ & $3 \%$ \\
\hline Follow-up & 2 years & $\sim 6$ months & Median 8 months (4-15 months) & 12 months \\
\hline
\end{tabular}


poor long-term glycaemic control and presence of systemic ischaemia and ischaemic retinopathy. Missed pre-surgical appointments by the patient results in both delay of planned operation and progression of traction component, which further compromises anatomical and visual outcomes in the thin retinae. The results in this series are from two main teaching hospitals in the UK that have well-established vitreo-retinal services and hence a shorter mean waiting time of 2.24 months, which may not be achievable in smaller single surgeon units and results in longer delays from failed attendance at appointments by the patient.

There is increasing evidence supporting off-label use of bevacizumab as a pharmacological adjunct in proliferative diabetic retinopathy before surgery. This has been shown to facilitate surgery ${ }^{14}$ and reduce the incidence of PVVH. ${ }^{15}$ Postoperative vitreous haemorrhage occurred in $43.25 \%$ (Table 5) of the cases, but with only $11.35 \%$ recurring after first operative day. In all, $17 / 185$ eyes $(9.12 \%)$ required reoperation to clear vitreous haemorrhage. However, we found no difference in the number of episodes of late PVVH with the use of bevacizumab. Other authors have recommended entrysite cryotherapy or laser, which reduces the incidence of PVVH by 50\%. ${ }^{16}$ However, these results need further validation by larger randomised controlled trials.

Maculopathy in diabetes is a multi-factorial condition with both posterior vitreous traction and increased VEGF levels as possible causal factors known in the pathogenesis of macular oedema. ${ }^{17}$ Recent studies on the use of bevacizumab alone or in combination with intravitreal triamcinolone for treatment of macular oedema have shown up to +5 letters gain as compared with laser alone at the end of 12 months. ${ }^{18,19}$ In our cohort, fewer eyes who had received intravitreal bevacizumab before vitrectomy required laser treatment for maculopathy, than those who had received vitrectomy alone in group A. This was of marginal significance and was possibly due to small numbers, but large randomized trials are needed in future. Additional benefit might have been due to patients receiving additional endolaser at surgery and increased oxygenation levels achieved with vitrectomy. ${ }^{20}$

To summarize, both visual and anatomical results have improved following vitrectomy in patients with endstage diabetic eye disease. There was no significant effect of ethnicity on the final visual outcome; however, pre-surgical appointments missed by patients severely affected the final outcome. The authors are aware of the limitation caused by the retrospective nature of the study. The information from this study could be used to provide informed consent and could also help to counsel patients about the need to keep up with their appointments. This will improve their chances of successful visual outcome and may reduce the costs of visual impairment to the state due to sight impairment.

\section{Summary}

What was known before

- Visual outcome following vitrctomy for proliferative diabetic retinopathy.

\section{What this study adds}

- Visual outcome following vitrectomy outcome for end stage diabetic retinal disease with respect to ethnicity.

- Impact of systemic -comorbidities on visual outcome.

- Impact of failed clinical appointment on visual outcome.

\section{Conflict of interest}

The authors declare no conflict of interest.

\section{References}

1 Resnikoff S, Pascolini D, Etya'ale D, Kocur I, Pararajasegaram R, Pokharel GP et al. Global data on visual impairment in the year 2002. Bull World Health Organ 2004; 82(11): 844-851.

2 Zimmet P, Alberti KG, Shaw J. Global and societal implications of the diabetes epidemic. Nature 2001; 414(6865): 782-787.

3 Fine SL, Patz A. Ten years after the Diabetic Retinopathy Study. Ophthalmology 1987; 94(7): 739-740.

4 The Diabetic Retinopathy Vitrectomy Study Research Group. Early vitrectomy for severe vitreous hemorrhage in diabetic retinopathy. Two-year results of a randomized trial. Diabetic Retinopathy Vitrectomy Study report 2. Arch Ophthalmol 1985; 103(11): 1644-1652.

5 Williams DF, Williams GA, Hartz A, Mieler WF, Abrams GW, Aaberg TM. Results of vitrectomy for diabetic traction retinal detachments using the en bloc excision technique. Ophthalmology 1989; 96(6): 752-758.

6 Arevalo JF, Wu L, Sanchez JG, Maia M, Saravia MJ, Fernandez $\mathrm{CF}$ et al. Intravitreal bevacizumab (Avastin) for proliferative diabetic retinopathy: 6-months follow-up. Eye (Lond) 2009; 23(1): 117-123.

7 Gregori NZ, Feuer W, Rosenfeld PJ. Novel method for analyzing snellen visual acuity measurements. Retina 2010; 30(7): 1046-1050.

8 Yorston D, Wickham L, Benson S, Bunce C, Sheard R, Charteris D. Predictive clinical features and outcomes of vitrectomy for proliferative diabetic retinopathy. Br J Ophthalmol 2008; 92: 365-368.

9 Mason III JO, Colagross CT, Haleman T, Fuller JJ, White MF, Feist RM et al. Visual outcome and risk factors for light perception and no light perception vision after vitrectomy for diabetic retinopathy. Am J Ophthalmol 2005; 140(2): 231-235.

10 Smiddy WE, Feuer W, Irvine WD, Flynn Jr HW, Blankenship GW. Vitrectomy for complications of proliferative diabetic retinopathy. Functional outcomes. Ophthalmology 1995; 102(11): 1688-1695.

11 Yorston D, Wickham L, Benson S, Bunce C, Sheard R, Charteris D. Predictive clinical features and outcomes 
of vitrectomy for proliferative diabetic retinopathy. Br J Ophthalmol 2008; 92(3): 365-368.

12 Thompson JT, de BS, Michels RG, Rice TA, Glaser BM. Results of vitrectomy for proliferative diabetic retinopathy. Ophthalmology 1986; 93(12): 1571-1574.

13 DRVS. Early vitrectomy for severe proliferative diabetic retinopathy in eyes with useful vision. Results of a randomized trial-Diabetic Retinopathy Vitrectomy Study Report 3. The Diabetic Retinopathy Vitrectomy Study Research Group. Ophthalmology 1988; 95(10): 1307-1320.

14 Rizzo S, Genovesi-Ebert F, di BE, Vento A, Miniaci S, Williams G. Injection of intravitreal bevacizumab (Avastin) as a preoperative adjunct before vitrectomy surgery in the treatment of severe proliferative diabetic retinopathy (PDR). Graefes Arch Clin Exp Ophthalmol 2008; 246(6): 837-842.

15 da RL, Ribeiro JA, Costa RA, Barbosa JC, Scott IU, de Figueiredo-Pontes LL et al. Intraoperative bleeding during vitrectomy for diabetic tractional retinal detachment with versus without preoperative intravitreal bevacizumab (IBeTra study). Br J Ophthalmol 2009; 93(5): 688-691.
16 Steel DH, Connor A, Habib MS, Owen R. Entry site treatment to prevent late recurrent postoperative vitreous cavity haemorrhage after vitrectomy for proliferative diabetic retinopathy. Br J Ophthalmol 2010; 94(9): 1219-1225.

17 Bandello F, Battaglia PM, Lanzetta P, Loewenstein A, Massin P, Menchini F et al. Diabetic macular edema. Dev Ophthalmol 2010; 47: 73-110.

18 Kook D, Wolf A, Kreutzer T, Neubauer A, Strauss R, Ulbig $\mathrm{M}$ et al. Long-term effect of intravitreal bevacizumab (avastin) in patients with chronic diffuse diabetic macular edema. Retina 2008; 28(8): 1053-1060.

19 Soheilian M, Ramezani A, Obudi A, Bijanzadeh B, Salehipour M, Yaseri M et al. Randomized trial of intravitreal bevacizumab alone or combined with triamcinolone versus macular photocoagulation in diabetic macular edema. Ophthalmology 2009; 116(6): 1142-1150.

20 Stefansson E. The therapeutic effects of retinal laser treatment and vitrectomy. A theory based on oxygen and vascular physiology. Acta Ophthalmol Scand 2001; 79(5): 435-402. 